\title{
Synthesis of texaphyrin conjugates
}

\author{
D. J. Magda
}

Z. Wang

Nikolay Gerasimchuk

W. H. Wei

P. Anzenbacher

See next page for additional authors

Follow this and additional works at: https://bearworks.missouristate.edu/articles-cnas

\section{Recommended Citation}

Magda, Darren J., Zhong Wang, Nikolay Gerasimchuk, W-H. Wei, Pavel Anzenbacher, and Jonathan L. Sessler. "Synthesis of texaphyrin conjugates." Pure and applied chemistry 76, no. 2 (2004): 365-374.

This article or document was made available through BearWorks, the institutional repository of Missouri State University. The work contained in it may be protected by copyright and require permission of the copyright holder for reuse or redistribution.

For more information, please contact BearWorks@library.missouristate.edu. 


\section{Authors}

D. J. Magda, Z. Wang, Nikolay Gerasimchuk, W. H. Wei, P. Anzenbacher, and J. L. Sessler 


\title{
Synthesis of texaphyrin conjugates*
}

\author{
Darren J. Magda ${ }^{1}$, Zhong Wang ${ }^{1}$, Nikolay Gerasimchuk ${ }^{1}$, \\ Wenhao Wei ${ }^{2}$, Pavel Anzenbacher, Jr. ${ }^{2}$, and Jonathan L. Sessler ${ }^{2, \ddagger}$ \\ ${ }^{1}$ Pharmacyclics Incorporated, 995 East Arques Avenue, Sunnyvale, CA \\ 94085-4593 USA, ${ }^{2}$ Department of Chemistry \& Biochemistry, 1 University Station - \\ A5300, The University of Texas at Austin, Austin, TX 78712-0165, USA
}

\begin{abstract}
This paper summarizes recent synthetic efforts devoted to the generation of new, second-generation texaphyrin-type drugs, specifically species that involve known or potential anticancer agents covalently attached to a tumor-localizing texaphyrin core. Particular emphasis will be placed on the strategies needed to prepare such systems, as well as on the choice of active group being subject to attachment.
\end{abstract}

\section{INTRODUCTION}

In spite of considerable progress in recent years, cancer remains the second leading cause of death in the United States [1]. Finding new ways to diagnose and treat cancer thus remains a formidable challenge of great current concern. Among the various conceivable approaches for developing improved cancer therapies, one that is particularly appealing involves using a cancer-targeting small molecule as a carrier to deliver in a tumor-specific manner various known, or promising, chemotherapeutic agents. Such a strategy, in turn, would allow these latter agents to be more effective, at least in many cases. At present, there are a substantial number of approved pharmaceutical agents in the oncology area whose therapeutic ratio is known to be less than ideal. However, these same agents could be made more potent were they to be brought directly to tumors in greater local concentration. Likewise, they could be rendered less toxic were they modified so as to promote clearance from the body through different excretion pathways. Attaching these species to site-localizing small molecules might allow both these objectives to be attained; it would provide hybrid systems, so-called conjugates, with unique cancer uptake and whole body clearance properties. While this idea is not new, implementing it in a clinically effective way has proved challenging. Not only must care be given to the choice of putative anticancer agent and the specifics of the linking groups used to tether it covalently to the site-directing small molecule, one must actually find a system or systems that can function in the latter capacity, i.e., act as a cancer-localizing carrier in a safe and effective manner. Here, it is thought, the texaphyrins could have a useful role to play.

The texaphyrins are pentaaza Schiff-base derived expanded porphyrins that are known to form stable 1:1 complexes with many metal cations, including those of the trivalent lanthanide series. The gadolinium(III) complex of one particular texaphyrin derivative, motexafin gadolinium (MGd; $\left.\mathrm{Xcytrin}^{\circledR} ; \mathbf{1}\right)$, has been extensively studied as a potential MRI detectable enhancer of X-ray cancer therapy [2-9]. Clinical studies have confirmed that this agent is taken up into and retained in tumors with high specificity (cf., e.g., Fig. 1) [6-9]. They have also served to establish that this agent could be administered safely to cancer patients at the $5 \mathrm{mg} / \mathrm{kg}$ dose level over the course of a two-week dosing reg-

\footnotetext{
*Plenary lecture presented at the $2^{\text {nd }}$ Santa María Workshop on Chemistry Devoted to Bioinorganic Chemistry, Santa María del Mar, Havana, Cuba, 7-11 July 2003. Other presentations are published in this issue, pp. 321-388.

${ }^{\ddagger}$ Corresponding author
} 


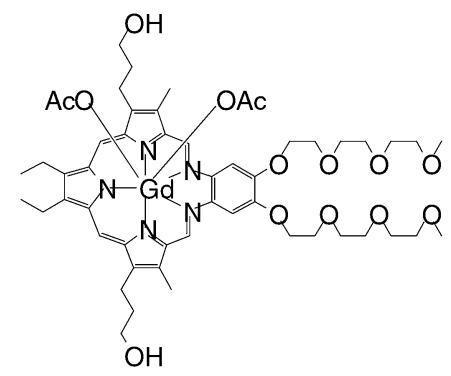

1

(motexafin gad ol inium; MGd)

imen [9]. Various supporting studies revealed a clearance pathway that was predominantly hepatic [3] and provided support for a very novel mechanism of action. This latter, manifest in terms of increased apoptosis [10,11], is believed to involve redox modulation processes that take place outside of the nucleus [12]. The fact that this particular texaphyrin-type species was known to localize in tumors, coupled with the fact that it was believed to act via a mechanism that was "orthogonal" to those of standard cancer chemotherapeutics, led to the consideration that MGd, $\mathbf{1}$, could provide the tumor-localizing, biocompatible core needed to generate cancer-seeking conjugates. In this paper, initial synthetic efforts targeting the production of such conjugates are reviewed.
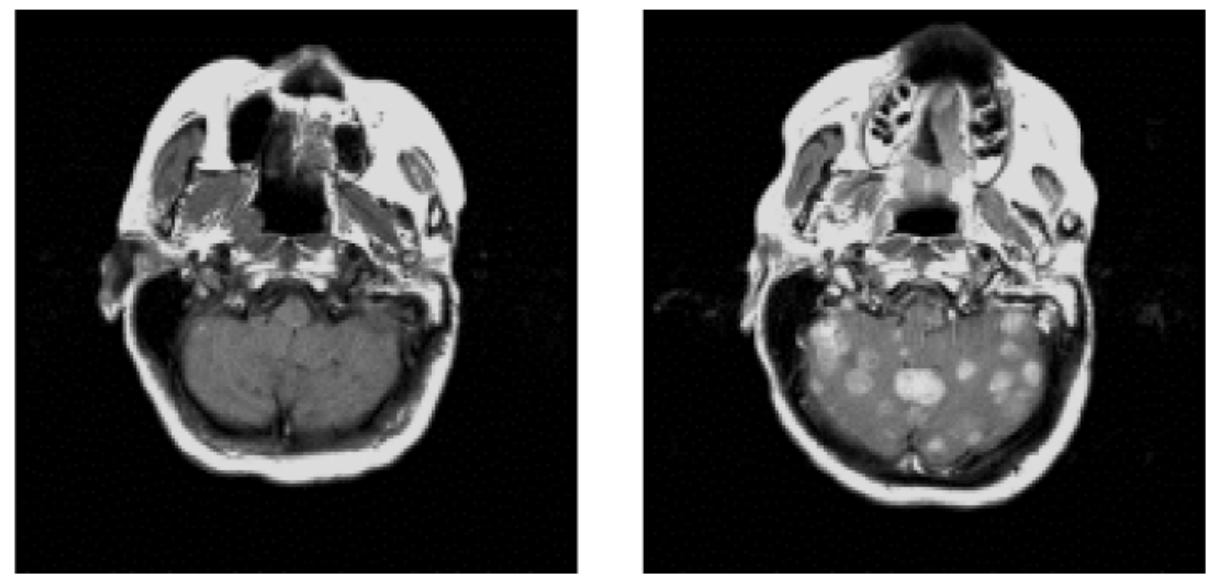

Fig. 1 T1-weighted brain MRI scans of a patient with non-small-cell lung cancer: Left, noncontrast scan at baseline; right, noncontrast scan after the $10^{\text {th }}$ daily administration of motexafin gadolinium (MGd) at a dose level of $5 \mathrm{mg} / \mathrm{kg} / \mathrm{day}$. The enhanced brightening seen in the image on the right is due to localization of texaphyrin agent in various cancerous lesions. This figure was reproduced with permission from ref. [8] to which the reader is referred for further details. Copyright 2002 American Society for Clinical Oncology.

Figure 2 is designed to illustrate the texaphyrin-based approach to anticancer conjugate preparation. As can be seen from inspection of this figure, two key design aspects can be considered above and beyond the predicative selection of texaphyrin as the localizing core. These involve, respectively, the choice of (1) the linking subunit and (2) the active agent to be attached. From a synthetic perspective, therefore, the problem of designing and preparing texaphyrin anticancer agent conjugates, hereafter referred to as "conjugates", boiled down to developing appropriate, and hopefully generalizable, linking strategies and choosing known or potential chemotherapeutic agents whose efficacy could be expected 


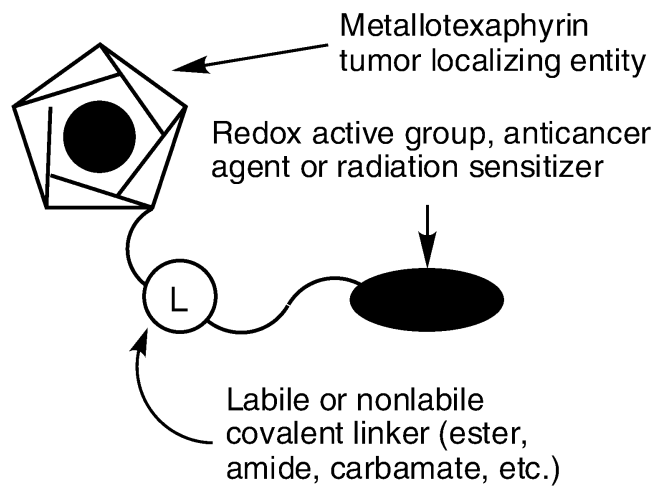

Fig. 2 Schematic illustration of the texaphyrin conjugate concept.

to benefit from being appended to a biolocalizing texaphyrin core. A further question involved the matter of whether a given conjugate system would benefit from the presence of a so-called fusible linker, specifically a tethering construct that would be labile in intracellular milieus. Naturally, the initial choice of synthetic targets, as reported here, reflected an interplay of all such considerations.

\section{CONJUGATES BASED ON REDOX ACTIVE GROUPS}

As implied above, considerable effort has been devoted to elucidating possible mechanisms of action for Xcytrin (MGd, 1). As the result of these investigations, it is now believed that this gadolinium(III) texaphyrin complex mediates its radiation therapy enhancing effect in whole or in part by acting as a redox cycling agent [10]. In particular, as shown schematically in Fig. 3, it is proposed that MGd serves to capture electrons from reducing metabolites, such as ascorbate anion, and transfers them to dioxygen in a one-electron process to produce superoxide [13] that, in vivo, is quickly converted to hydrogen peroxide. The result of this action is the production of a reactive oxygen species, peroxide, that is a known

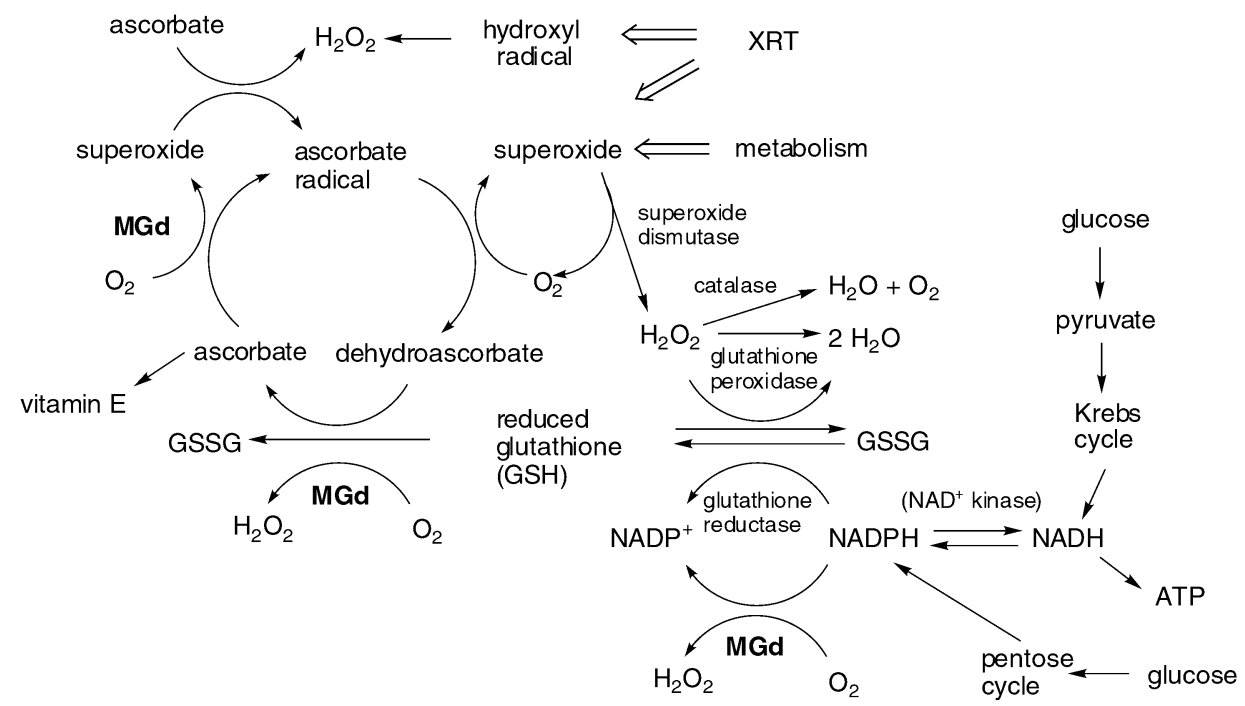

Fig. 3 Mechanistic rationale for the metabolism-based effects produced by motexafin gadolinium (Xcytrin; MGd), a gadolinium(III) texaphyrin complex, under conditions of XRT sensitization. This figure is a modification of one that first appeared in ref. [10]. 
apoptosis triggering agent [14], as well as the loss of reducing metabolites, including both ascorbate and glutathione, that serve to mitigate the effects of both ionizing radiation and oxidative stress. Specific support for this mechanism comes from the finding that adding ascorbate to the medium enhances the direct cytotoxic potency of MGd in cell culture, as does L-buthionine- $S, R$-sulfoximine (BSO) [10]. BSO is an irreversible inhibitor of an enzyme involved in glutathione biosynthesis $(\gamma$-glutamylcysteine synthetase) [15]. Widely used in biochemical studies, work with BSO has helped underscore the role of glutathione in preventing oxidative damage by reactive oxygen species. Presumably as a consequence, BSO has also been found to provide a radiation-enhancing effect in vitro, especially when used in conjunction with other sensitizing agents [16-20]. Unfortunately, BSO lacks the safety and efficacy profiles needed to make it attractive as a drug candidate. On the other hand, the combination of apparent mechanistic synergy (i.e., enhancing the in vitro efficacy of MGd) and potential independent utility were its therapeutic ratio of efficacy to toxicity improved made it an ideal candidate for conjugation to a texaphyrin core.

Scheme 1 summarizes the procedure used to prepare a first, prototypical MGd-BSO conjugate (2). Specifically, the BSO amino functionality was first protected as the Fmoc (9-fluorenylmethoxycarbonyl) derivative to produce a functionalized carboxylic acid derivative suitable for coupling to the hydroxyl groups present in $\mathbf{1}$. While in principle, this latter coupling step could be carried out in a number of ways, it was found that the use of a Mitsunobu-type procedure (DEAD- $\mathrm{Ph}_{3} \mathrm{P}$ activation) was extremely efficient; it produced the desired product (2) in $36 \%$ yield after Fmoc deprotection. This yield was considered to be quite good in light of the fact that a statistical mixture of products (unreacted MGd, doubly functionalized MGd, and singly functionalized MGd) was produced during the key coupling step.

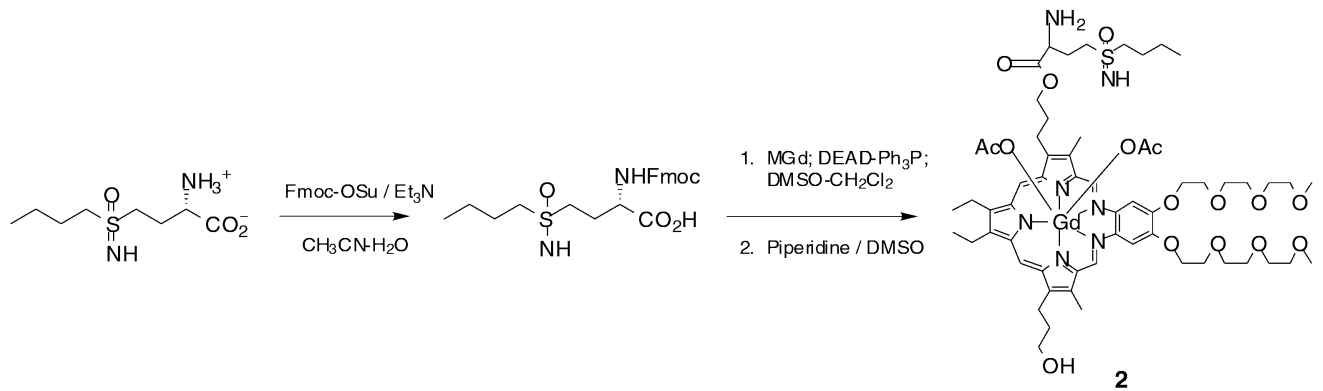

Scheme 1 Synthesis of BSO texaphryin conjugate 2. Here, DEAD = diethyl azodicarboxylate and Fmoc = 9-fluorenylmethoxycarbonyl.

One of the reasons the Mitsunobu coupling methodology was considered so attractive was that it would provide a general means of producing a broad range of conjugates directly from nucleophiles bearing acidic protons. As a test of this proposal, the bis-nitroimidazole derivative $\mathbf{3}$ was prepared as shown in Scheme 2. Likewise, a dimethoxytrityl (DMT) protected, monoamine substituted version of MGd (5) was also prepared in ca. $35 \%$ yield via the corresponding phthalimide derivative (Scheme 3); in this case, the starting material was the mono-DMT texaphyrin 4 produced by reacting MGd with DMT chloride under statistical conditions.

The rationale behind the synthesis of the amine derivatives is that they would provide MGd derivatives equipped with a nucleophilic site to which a range of electrophiles could be attached via, e.g., acylation. By contrast, the rationale for producing conjugate $\mathbf{2}$ is that it could produce a more effective radiation-sensitizing system. Nitroimidazoles have long been recognized for their potential as radiation sensitizers [21]. These species, known to be effective antifungal agents, are easy to reduce (electron affinic in the parlance of the radiation-sensitizing community) and have been used off-label as adjuvants for radiation therapy for some time. However, their lack of tumor-localizing specificity and the high systemic toxicity they display have tended to limit their wide spread clinical use [21-23]. Similar consid- 


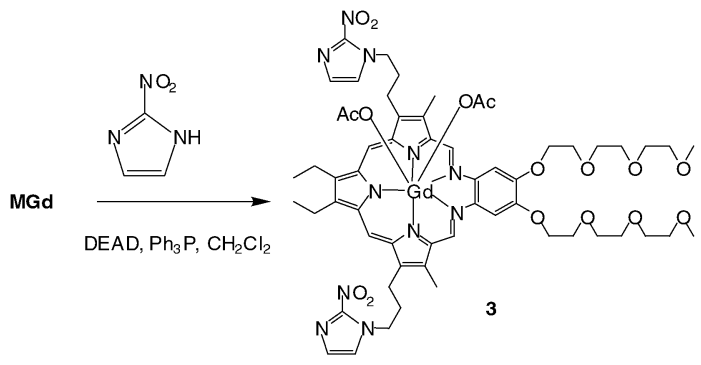

Scheme 2 Synthesis of bis-nitroimidazole texaphryin conjugate 3.
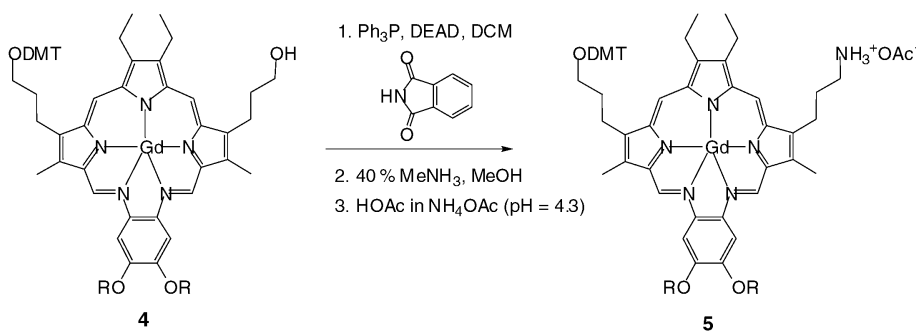

Scheme 3 Synthesis of the dimethoxytrityl (DMT) protected monoamine MGd derivative, 5.

erations have also precluded their being approved by the FDA as radiation sensitizers. On the other hand, coupling nitroimidazole subunits to a texaphyrin core could serve to enhance their biolocalization properties while, possibly, reducing their systemic toxicity. To the extent this proved true, it would likely increase their clinical utility.

\section{CONJUGATES BASED ON KNOWN CHEMOTHERAPEUTIC AGENTS}

The desire to produce a conjugate containing a redox-active subunit that was also a known cytotoxin inspired the synthesis of the doxorubicin conjugate 6. Doxorubicin (adriamycin) is one of the most important chemotherapeutic agents currently in use. While its mode of action is not thought to be related to electron-transfer processes per se, the fact that it contains easy-to-reduce quinone functionality, could be important in terms of its dose-limiting cardiomyopathy; capture of an electron by this subunit (from, e.g., $\mathrm{NAD}(\mathrm{P}) \mathrm{H})$ followed by production of reactive oxygen species may trigger a cytotoxic reaction at sites other than within the cancerous tissues [24-34]. The possibility that this kind of chemical process could occur, led to studies wherein doxorubicin was administered in conjunction with MGd, 1 [35]. The fact that an enhanced effect was noted in these in vivo experiments made doxorubicin of particular interest as a potential "active agent" for attachment to a texaphyrin. Augmenting the interest in such systems was the possibility that the resulting conjugate might localize in tumors and display a redox-based mechanism of action that is enhanced relative to that illustrated in Fig. 2.

The synthesis of the doxorubicin texaphyrin conjugate $\mathbf{6}$ is shown in Scheme 4. It relies on the use of an acetate ester to protect one of the hydroxypropyl subunits present in MGd and use of disuccinimidyl carbonate (DSC) to activate the other. This sequence of two steps gives intermediate $\mathbf{7}$ in $25 \%$ yield. Further reaction with the amine group of doxorubicin then provides conjugate 6 in $24 \%$ yield. A noteworthy aspect of this system is that, even though doxorubicin is a strong chromophore in its own right, the visible spectrum of $\mathbf{6}$ is virtually unchanged compared to that of $\mathbf{1}$ (dominant Soretlike absorptions at $470 \mathrm{~nm}$ in both cases), except for the presence of relative weak bands at 558 and $596 \mathrm{~nm}$ that are ascribed to the doxorubicin moiety and a slight red-shift in the far-red Q-band $\left(\lambda_{\max }=\right.$ $748 \mathrm{~nm}$ for $\mathbf{6}$ vs. $740 \mathrm{~nm}$ for $\mathbf{1}$ ). 


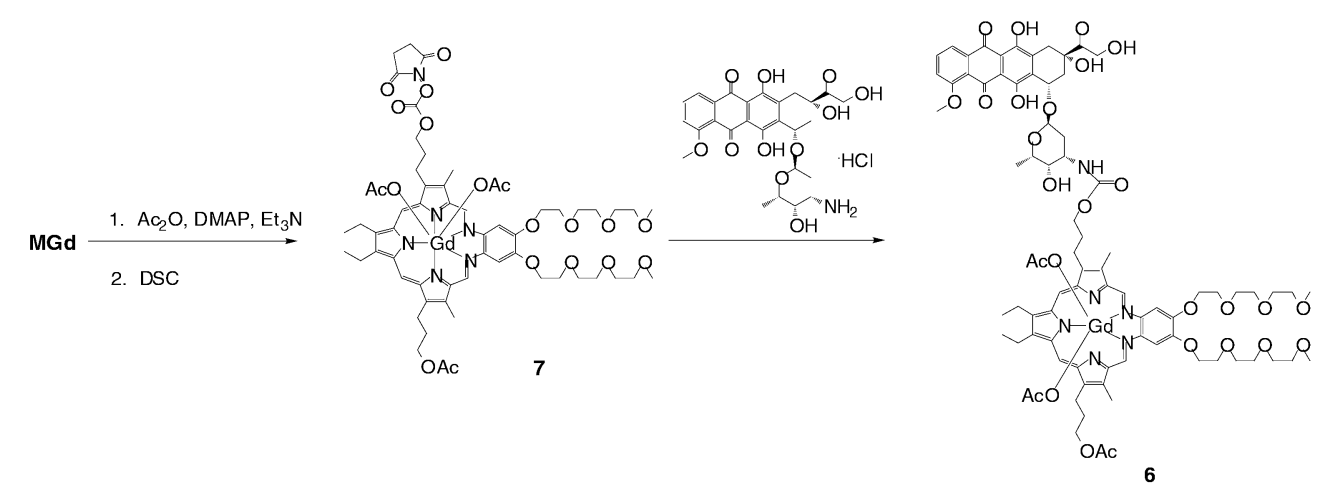

Scheme 4 Synthesis of doxorubicin texaphyrin conjugate 6. Here, DMAP = dimethylaminopyridine and DSC = $\mathrm{N}, \mathrm{N}^{\prime}$-disuccinimidyl carbonate.

Another of the most prevalent of all anticancer agents is cisplatin. It and its two FDA-approved analogs, carboplatin and oxaliplatin, have proved remarkably effective for a range of tumor types, including most notably testicular cancer in the case of cisplatin. However, the high toxicity of these species [36], particularly the nephrotoxicity displayed by cisplatin itself, leads to the consideration that conjugation to texaphyrin, which might obviate the normal renal clearance pathways seen for this drug, could lead to improved therapeutic agents. Here, the fact that the presence of a texaphyrin "core" is expected to impart a degree of tumor-specific localization is considered to represent a potentially ancillary advantage. On the other hand, because cisplatin is thought to mediate its effect at the DNA level [37-39], it was likewise recognized that for the cisplatin-texaphyrin conjugate strategy to prove effective, either the whole molecular ensemble would have to enter into the nucleus or release of an active diamino platinum(II) center from the conjugate would have to occur. While the latter eventuality could perhaps be engineered, through the construction of, e.g., a system containing a fusible linkage, the synthetic difficulties associated with the "simple" construction of any cisplatin-texaphyrin conjugate led us to focus first on the preparation of cisplatin-texaphyrin conjugates containing nonlabile linkages. As described below, two such conjugates have now been prepared.

The synthesis of the first cisplatin-texaphyrin conjugate, $\mathbf{8}$, is shown in Scheme 5. Here, the key intermediate is the doubly $\mathrm{N}$-protected dinitrocatechol derivative 9. This species was prepared in four steps and in $19 \%$ overall yield from 2-[2-(2-chloroethoxy)ethoxy]ethanol (10) by converting it to its corresponding $N$-benzyl derivative (11) by reaction with benzylamine. This $N$-benzylated species, a secondary amine, was treated with first 2-bromophthalimide and then methanesulfonyl chloride to give $\mathbf{1 2}$. Reaction with the "monopegylated" dinitrocatechol derivative 13 [40] then produced 9. Hydrogenation over Pearlman's catalyst then provided the corresponding diamine.

Since this species proved unstable, it was used immediately; in particular, it was reacted with the diformyl tripyrrane 14, to produce the " $\mathrm{sp}_{3}$ form" of the desired texaphyrin, 15. Again, this species proved unstable and so the crude product was metalated immediately to give the gadolinium(III) complex 16 in roughly $90 \%$ yield based on $\mathbf{9}$. $N$-deprotection, gave the intermediate $\mathbf{1 7}$ in $20 \%$ yield, while subsequent treatment with $\mathrm{K}_{2} \mathrm{PtCl}_{4}$ then gave the desired $\mathrm{Pt}(\mathrm{II})$ complex 8 in roughly $40 \%$ yield. Unfortunately, this species proved too insoluble (in both aqueous and nonaqueous media) to allow for characterization by methods other than UV-vis spectroscopy and mass spectrometry. 
<smiles>COCCOCCOCCN(CCOCCOCCOCCNc1ccccc1)CCN1C(=O)c2ccccc2C1=O</smiles>

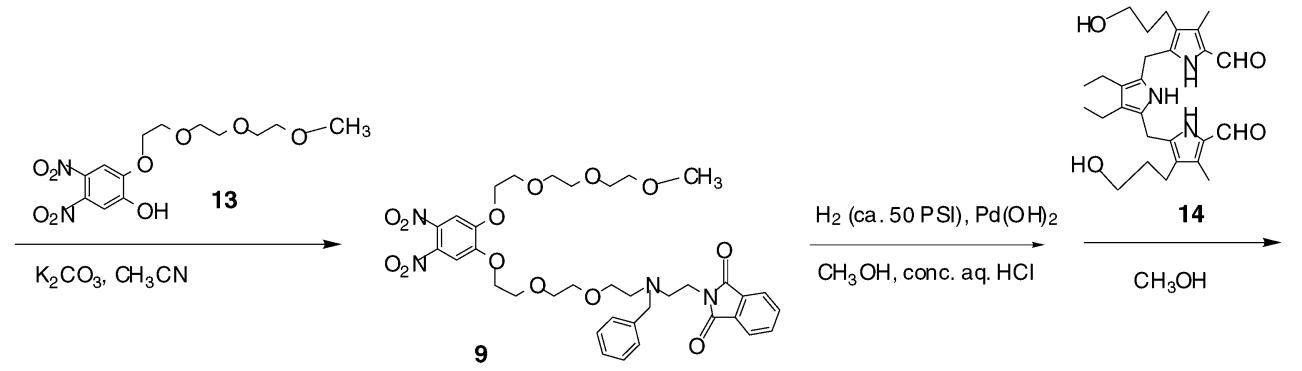

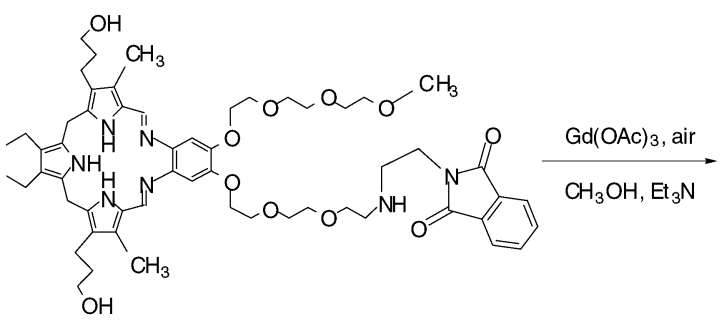

15

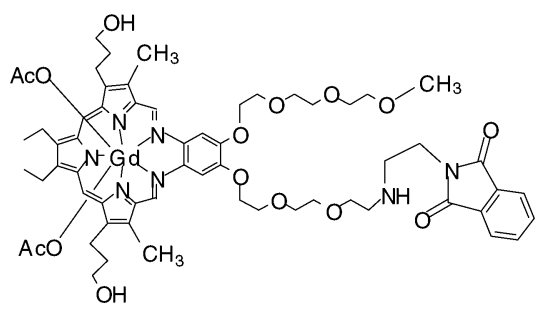

16

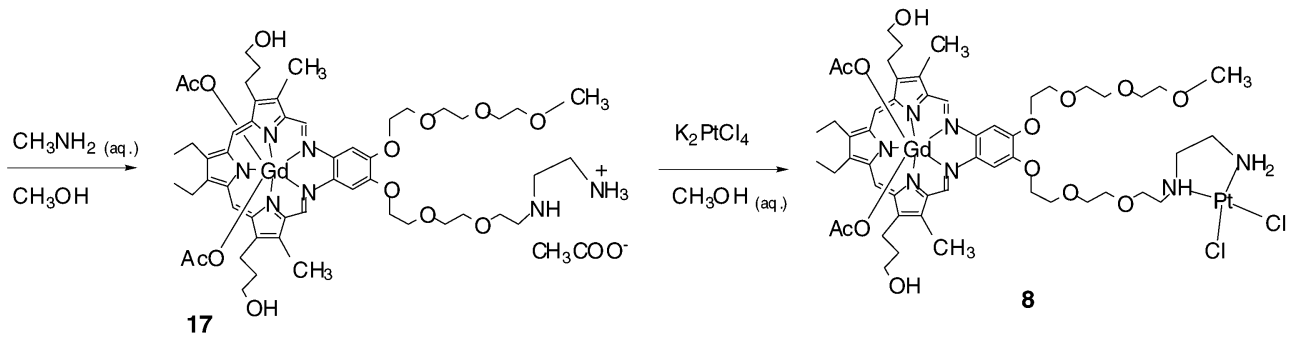

Scheme 5 Synthesis of the diamine-based cis-Pt gadolinium(III) texaphyrin conjugate $\mathbf{8}$. Here, $\mathrm{MsCl}$ represents methanesulfonyl chloride.

The second conjugate was designed to provide a species with improved solubility characteristics. Toward this end, conjugate 18 was prepared as shown in Scheme 6. Again, the key intermediate was the elaborated dinitrocatechol derivative 19. It was prepared in $16 \%$ yield (based on 20 ) by reacting the solubilized piperazine derivative $\mathbf{2 1}$ with tosylate 22. Once this species was in hand, reduction to the diamine, followed by immediate reaction with the same diformyl tripyrrane used to prepare 15 (i.e., 14), gave 23 in $87 \%$ yield. Treatment with gadolinium acetate under standard oxidative insertion conditions provided texaphyrin 24 in ca. $30 \%$ yield. This species was then converted into the corresponding platinum complex 18 in ca. $40 \%$ yield by reacting with potassium tetrachloroplatinate in water. 


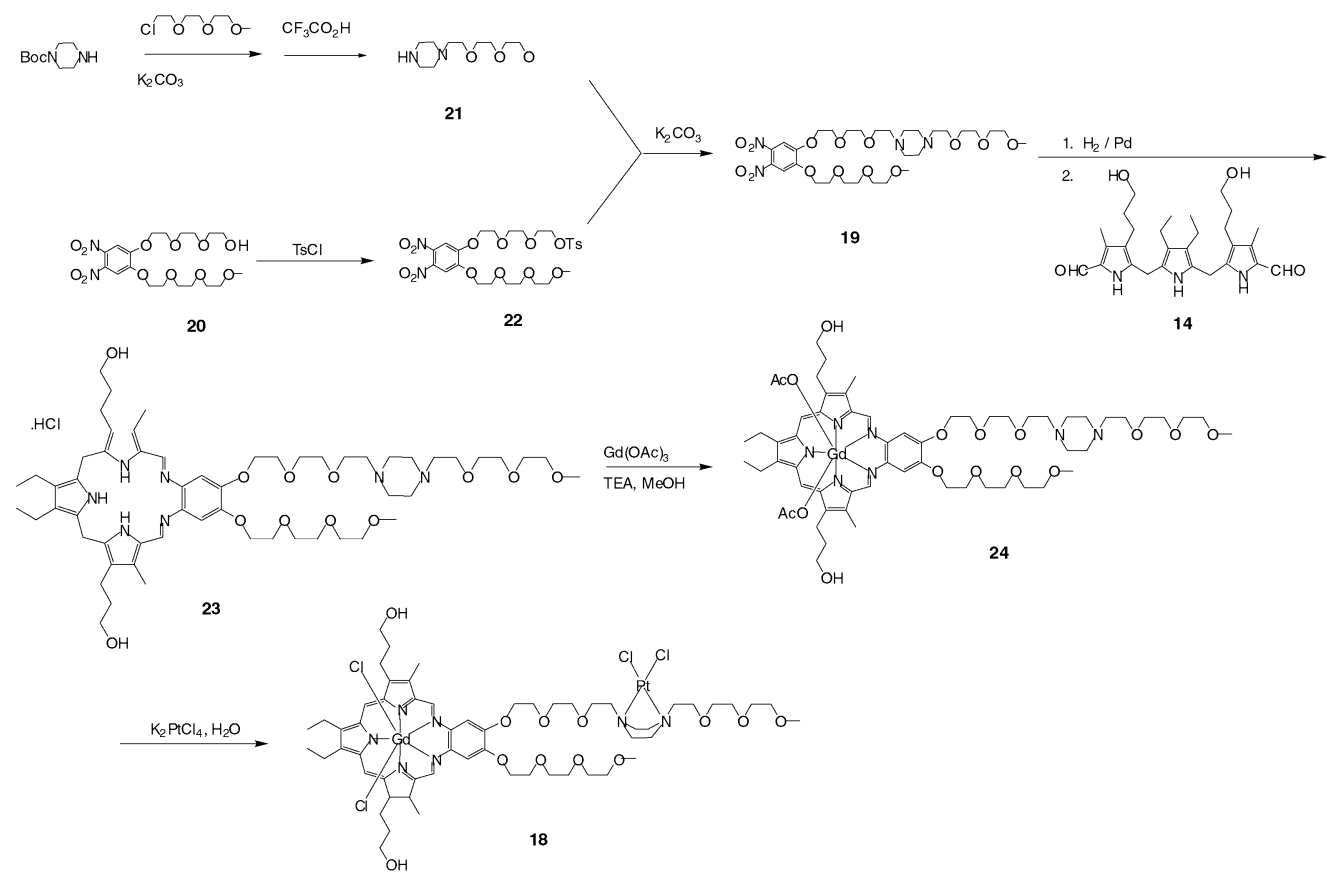

Scheme 6 Synthesis of the piperazine-based cis-Pt gadolinium(III) texaphyrin conjugate 18.

Unfortunately, like its congener $\mathbf{8}$, complex $\mathbf{1 8}$ proved too insoluble to permit analysis by any means other than UV-vis spectroscopy and mass spectrometry.

Recently, a set of water-soluble texaphyrin conjugates has been prepared. They rely on the use of methotrexate, 25, rather than cis-Pt, as the active chemotherapeutic group. Methotrexate is a cell cycle inhibitor that has a well-recognized role in oncology and is an agent that is used widely in conjunction with other cancer drugs [41-43]. Thus, potentiation of methotrexate by MGd might be anticipated, and has indeed been reported in in vitro models [44]. Further, because methotrexate bears diacid functionality and is thus inherently water-soluble, it was thought that it could be used to construct conjugates that retain some degree of water solubility. In accord with such thinking, the ester and amide linked conjugates 26 and 27 were prepared in $18 \%$ and $10 \%$ yield, respectively. They were obtained by subjecting the DMT-protected alcohol and amine $\mathbf{4}$ and $\mathbf{5}$ to reaction with methotrexate in the presence of EDC [1-ethyl-3-(3- dimethylaminopropyl)carbodiimide hydrochloride] and diisopropylethylamine/dimethylformide and then subsequently deprotecting by treatment with acetic acid in dichloromethane. In both cases, a small amount of the isomeric product, resulting from reaction at the other carboxylic acid site, was obtained. While displaying spectral characteristics analogous to those of $\mathbf{2 6}$ and $\mathbf{2 7}$, these isomeric materials displayed different retention times on HPLC and could be isolated by such means. Such isolation was specifically performed in the case of $\mathbf{2 7}$. Nonetheless, for the purposes of initial biological testing such separations were not deemed necessary. Rather, it was thought that $\mathbf{2 6}$ and $\mathbf{2 7}$, by virtue of being chemically pure (if not necessarily isomerically pure) and, in contrast to $\mathbf{8}$ and $\mathbf{1 8}$, appreciably water soluble, would permit cell studies to be carried out.

\section{FUTURE PROSPECTS}

Currently, in vitro tests of $\mathbf{2 6}$ and $\mathbf{2 7}$ are in progress. Although, the results of these analyses are not yet known, the availability of two different kinds of methotrexate-gadolinium(III) texaphyrin conjugates is considered significant. It should allow, at least in principle, one to address the critical question of 

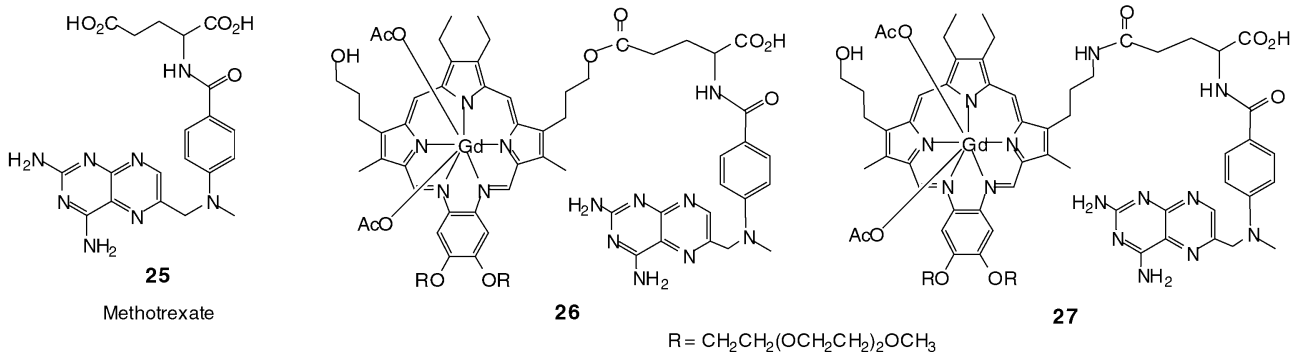

whether a labile or nonlabile linkage is preferred. For instance, studies of $\mathbf{2 6}$ are expected to provide insights into whether the benefit of a labile linkage, namely a presumed increased intracellular release of methotrexate, is overshadowed by a decrease in serum stability. Meanwhile, the amide-linked system $\mathbf{2 7}$ is expected to act as a "positive control" as regards the latter issue and provide a system that is quite stable in both extra- and intracellular loci. In experiments that could complement those designed to probe potency, cell uptake studies with $\mathbf{2 6}$ and $\mathbf{2 7}$ might make it possible to ascertain whether small changes in linkage polarity (i.e., amide vs. ester) lead to appreciable changes in cell uptake. Finally, more advanced in vivo studies might provide important insights into how, if at all, the choice of tethers modifies the tumor-targeting and clearance properties of a texaphyrin core. In any event, to the extent that differences are observed between these two conjugates, it would set the stage for the rational design of additional, yet-improved systems.

\section{ACKNOWLEDGMENT}

This work was supported in part by a grant from the National Institutes of Health (CA 68682 to J.L.S.).

\section{REFERENCES}

1. Cancer Facts and Figures-1999. American Cancer Society, Atlanta (1999).

2. S. W. Young, F. Quing, A. Harriman, J. L. Sessler, W. C. Dow, T. D. Mody, G. Hemmi, Y. Hao, R. A. Miller. Proc. Natl. Acad. Sci. USA 93, 6610 (1996). Correction: Proc. Natl. Acad. Sci. USA 96, 2569 (1999).

3. R. A. Miller, K. Woodburn, Q. Fan, M. Renschler, J. L. Sessler, J. A. Koutcher. Int. J. Biol. Radiat. Oncol. 45, 981 (1999).

4. J. L. Sessler and R. A. Miller. Biochem. Pharmacol. 59, 733 (2000).

5. T. D. Mody, L. Fu, J. L. Sessler. Progr. Inorg. Chem. 49, 551 (2001).

6. D. I. Rosenthal, P. Nurenberg, C. R. Becerra, E. P. Frenkel, D. P. Carbone, B. L. Lum, R. Miller, J. Engel, S. Young, D. Miles, M. F. Renschler. Clin. Cancer Res. 5, 739 (1999).

7. P. Carde, R. Timmerman, M. P. Mehta, C. D. Koprowski, J. Ford, R. B. Tishler, D. Miles, R. A. Miller, M. F. Renschler. J. Clin. Oncol. 19, 2074 (2000).

8. M. P. Mehta, W. R. Shapiro, M. J. Glantz, R. A. Patchell, M. A. Weitzner, C. A. Meyers, C. J. Schultz, W. H. Roa, M. Leibenhaut, J. Ford, W. Curran, S.-C. Phan, J. A. Smith, R. A. Miller, M. F. Renschler. J. Clin. Oncol. 20, 3445 (2002).

9. M. P. Mehta, P. Rodrigus, C. H. J. Terhaard, A. Rao, J. Suh, W. Roa, L. Souhami, A. Bezjak, M. Leibenhaut, R. Komaki, C. Schultz, R. Timmerman, W. Curran, J. Smith, S.-C. Phan, R. A. Miller, M. F. Renschler. J. Clin. Oncol. 21, 2529 (2003).

10. D. Magda, C. Lepp, N. Gerasimchuk, I. Lee, J. L. Sessler, A. Lin, J. Biaglow, R. A. Miller. Int. J. Radiat. Oncol., Biol., Phys. 51, 1025 (2001).

11. D. Magda, C. Lepp, N. Gerasimchuk, P. Lecane, R. A. Miller, J. E. Biaglow, J. L. Sessler. Chem. Commun. 2730 (2002). 
12. K. Woodburn. J. Pharmacol. Exp. Ther. 297, 888 (2001).

13. J. L. Sessler, N. A. Tvermoes, D. M. Guldi, G. L. Hug, T. D. Mody, D. Magda. J. Phys. Chem. 105, 1452 (2001).

14. E. Migliaccio, M. Giorgio, S. Mele, G. Pelicci, P. Reboidl, P. P. Pandolfi, L. Lanfrancone, P. G. Pelicci. Nature 402, 309 (1999).

15. A. Meister. Biochim. Biophys. Acta 1271, 35 (1995).

16. J. K. Dethmers and A. Meister. Proc. Natl. Acad. Sci. USA 78, 7492 (1981).

17. R. A. Kramer, M. Soble, A. E. Howes, V. P. Montoya. Int. J. Radiat. Oncol., Biol., Phys. 16, 1325 (1989).

18. N. J. McNally and J. A. Soranson. Int. J. Radiat. Oncol., Biol., Phys. 16, 1331 (1989).

19. D. W. Siemann, A. A. Flaherty, D. P. Penney. Int. J. Radiat. Oncol., Biol., Phys. 16, 1341 (1989).

20. M. F. Chen, L. T. Chen, H. W. Boyce, Jr. Anticancer Res. 15, 163 (1995).

21. E. J. Hall. Radiobiology for the Radiobiologist, $4^{\text {th }}$ ed., J. B. Lippincott, Philadelphia (1994).

22. J. M. Brown, N. Y. Yu, D. M. Brown, W. W. Lee. Int. J. Radiat. Biol. Oncol. Phys. 7, 695 (1981).

23. G. E. Adams, I. J. Stratford, R. G. Wallace, P. Wardman, M. E. Watts. J. Natl. Cancer Inst. 64, 555 (1980).

24. V. Berlin and W. A. Haseltine. J. Biol. Chem. 256, 4747 (1981).

25. J. H. Doroshow. Cancer Res. 43, 460 (1983).

26. G. C. Yeh, S. J. Occhipinti, K. H. Cowan, B. A. Chabner, C. E. Myers. Cancer Res. 47, 5994 (1987).

27. D. H. M. Lau, A. D. Lewis, B. I. Sikic. J. Natl. Cancer Inst. 81, 1034 (1989).

28. G. V. Rumyantseva, L. M. Weiner, E. I. Frolova, O. S. Fedorova. FEBS Lett. 242, 397 (1989).

29. B. K. Sinha, E. G. Mimnaugh, S. Rajagopalan, C. E. Myers. Cancer Res. 49, 3844 (1989).

30. A. D. Lewis, D. H. M. Lau, G. E. Duran, C. R. Wolf, B. I. Sikic. Cancer Res. 52, 4379 (1992).

31. E. Feinstein, E. Canaani, L. M. Weiner. Biochemistry 32, 13156 (1993).

32. J.-P. Gao, S. Friedman, K. W. Lanks. Cancer Chemother. Pharmacol. 33, 191 (1993).

33. G. Minotti, A. F. Cavaliere, M. Rossi, R. Schiavello, R. Zamparelli, G. Possati. J. Clin. Invest. 95, 1595 (1995).

34. D. H. M. Lau, G. E. Duran, A. D. Lewis, B. I. Sikic. Br. J. Cancer 70, 79 (1994).

35. R. A. Miller, K. W. Woodburn, Q. Fan, I. Lee, D. Miles, G. Duran, B. Sikic, D. Magda. Clin. Cancer Res. 7, 3215 (2001).

36. E. Wong and C. M. Ciandomenico. Chem. Rev. 99, 2451 (1999).

37. U. M. Ohndorf, M. A. Rould, Q. He, C. O. Pabo, S. J. Lippard. Nature 399, 708 (1999).

38. J. A. Dolling, D. R. Boreham, D. L. Brown, G. P. Raaphorst, R. E. Mitchel. Mutat. Res. 433, 127 (1999).

39. A. M. Di Francesco, A. Ruggiero, R. Riccardi. Cell. Mol. Life Sci. 59, 1914 (2002).

40. J. L. Sessler, D. J. Magda, P. Anzenbacher, Jr., S. Niezgoda, J. Carvalho. U.S. Patent No. $6,207,660$.

41. C. D. Blanke, M. Messenger, S. C. Taplin. Seminars Oncol. 24, 57 (1997).

42. E. Thomas and G. N. Hortobagyi. Endocrine-Related Cancer 10, 75 (2003).

43. N. Isaac, T. Panzarella, A. Lau, C. Mayers, P. Kirkbride, I. F. Tannock, K. A. Vallis. Cancer 95, 696 (2002).

44. D. Magda, C. Lepp, Q. Fan, P. Lecane, R. A. Miller. Am. Soc. Clin. Oncol. Proc. 22, 229 (2003). 